\title{
Development of physiological resistance and its stage specificity in Culex quinquefasciatus after selection with deltamethrin in Assam, India
}

\author{
Manas Sarkar ${ }^{1 /+}$, Indra K Bhattacharyya ${ }^{2}$, Aparajita Borkotoki ${ }^{3}$, Indra Baruah ${ }^{1}$, Ravi B Srivastava ${ }^{1}$ \\ ${ }^{1}$ Medical Entomology Division, Defence Research Laboratory, Post Bag 2, 784001 Tezpur, Assam, India ${ }^{2}$ Cotton College, Guwahati, India \\ ${ }^{3}$ Department of Zoology, Gawhati University, Guwahati, India
}

The study investigated the development and stage specificity of physiological resistance to insecticides in a colony of Culex quinquefasciatus Say (Diptera: Culicidae) mosquitoes, which are vectors of bancroftian filariasis in India, after selection with deltamethrin. Resistance was selected by exposing the larvae to the concentration of deltamethrin that caused $50 \%$ mortality in the tested population (i.e., $\left.L C_{50}\right)$. Under continuous selection pressure, the $L C_{50}$ increased steadily in subsequent generations. The estimated $L C_{50}$ for the $F_{0}$ generation was $0.409 \mu \mathrm{g} / \mathrm{L}$; the $L C_{50}$ first displayed a substantial increase in the $F_{5}$ generation $\left(5.616 \mu \mathrm{g} / \mathrm{L}\right.$ ) and reached $121.902 \mu \mathrm{g} / \mathrm{L}$ in the $F_{10}$ generation. The objective of this study was to establish a deltamethrin-resistant colony to develop a research programme that will study the evolution of physiological resistance patterns and stage-specific resistance responses in Cx. quinquefasciatus larvae and adults under laboratory conditions. An approximately 298-fold increase in resistance was recorded after 10 generations, as evidenced by the resistance ratio $\left(R R_{50}\right)$. The progress and effect of the selection pressure in the adult stage was monitored with the World Health Organisation (WHO) diagnostic test. The mortality, as observed using the WHO diagnostic test, declined significantly from the $F_{5}$ generation (85\%) onwards and the highest rate of survival (65\%) was observed in the $F_{10}$ generation.

Key words: Culex quinquefasciatus - deltamethrin - India - resistance - stage specificity - selection pressure

Resistance to chemical insecticides commonly used for mosquito control remains an important issue in India. Insecticide resistance occurs due to excessive and indiscriminate use of insecticides for vector and pest control. The spraying of DDT and $\mathrm{HCH}$ within public health programmes was introduced in India in the 1950s but mosquitoes developed resistance to these insecticides soon after its introduction. As a result, synthetic pyrethroids were introduced in some parts of India in the 1990s for selective control of multiple insecticideresistant vectors (Singh et al. 2002). Synthetic pyrethroids have shown great promise for pest control due to their low mammalian toxicity and their remarkable potency at low levels that quickly immobilises, kills and repels insects (Prasittisuk 1994, Chareonviriyaphap et al. 1997). Pyrethroids have been used for the impregnation of bed nets and for indoor residual spraying for vector control in many parts of the country due to their effectiveness and their rapid excito-repellent action.

Assam is the gateway of Northeastern India and is characterised meteorologically by a long rainy season and humid climate. Culex quinquefasciatus is abundant

Financial support: Defence Research \& Development Organisation, Ministry of Defence, Government of India

+ Corresponding author: manas_sarkar54491@yahoo.com

Received 11 August 2008

Accepted 19 March 2009 throughout Assam; it is a continuous biting nuisancemostly for those living close to larval habitats and poses a threat to human health as it transmits parasites that cause diseases such as bancroftian filariasis. In a tea agro ecosystem in Assam, the average infection rate of $C x$. quinquefasciatus with filarial worms was $4.6 \%$ and the overall prevalence of infective mosquitoes was $0.8 \%$, with an average load of third larval stage parasites (L3 load) of 2.0 per mosquito. It has been estimated that a total of 22,569 mosquito bites are received per person/year in tea gardens, of which 182 bites/person/ year $(0.806 \%)$ are infective (Mahanta et al. 2001). This species is considered sufficiently endophagous and anthropophilic and thus is more likely to come into contact with residual insecticides used for impregnated bed nets and indoor residual spraying.

Recent information on pyrethroid resistance in Assam is scarce due to the lack of consistent and carefully designed studies. The objective of this study was to establish a deltamethrin-resistant colony to develop a research programme that will study the evolution of physiological resistance patterns and life stage specificity of resistance responses in $C x$. quinquefasciatus under laboratory conditions. This resistant colony will be used to compare the resistance mechanisms and dynamics between field and laboratory-reared populations and to determine whether there is any possibility of extrapolating the laboratory results to the field. This will help to elucidate resistance mechanisms, which is essential for the planning of future insecticide resistance management programmes. 


\section{MATERIALS AND METHODS}

Mosquito strains and rearing - Cx. quinquefasciatus larvae were collected from Tezpur City in Assam and were reared in the insectary of the Medical Entomology Division of the Defence Research Laboratory, Tezpur, at $25 \pm 3^{\circ} \mathrm{C}$ and $80 \pm 10 \%$ relative humidity. Yeast powder was provided as larval food twice a day. Pupae were collected daily, transferred to small $(250 \mathrm{~mL})$ glass beakers containing clean aged water and placed in cages for adult emergence. Adult mosquitoes were provided with cotton soaked with a $10 \%$ sugar solution. Female mosquitoes were allowed to feed on a rabbit on the 3rd day after emergence. After 2-3 days, oviposition dishes were placed in the cages containing gravid females for egg laying. Eggs were collected and placed on enamel trays containing clean aged water for hatching. These adult mosquitoes were completely susceptible to deltamethrin, based on a standard World Health Organisation (WHO 1998) recommended adult susceptibility assay. The parent $\left(\mathrm{F}_{0}\right)$ colony was settled with approximately 6,000 adult mosquitoes.

Chemical insecticide - Technical grade deltamethrin (98.40\% pure) was obtained free of cost from Heranba Industries Ltd, Gujarat, India. All deltamethrin-impregnated papers were made as per the WHO standard procedure. The papers were treated with $2.75 \mathrm{~mL}$ per $180 \mathrm{~cm}^{2}$ of diagnostic concentration insecticide solution.

Selection of resistance - The susceptible strain of $C x$. quinquefasciatus was submitted to selection pressure in the larval stage with deltamethrin at a concentration that caused $50 \%$ mortality $\left(\mathrm{LC}_{50}\right)$. The $\mathrm{LC}_{50}$ values were estimated in each generation before selection. Deltamethrin stock $(0.001 \mathrm{mg} / \mathrm{mL}$ and $0.01 \mathrm{mg} / \mathrm{mL})$ was prepared by dissolving the required amount of technical grade deltamethrin in acetone and was stored at $4^{\circ} \mathrm{C}$. Groups of 20 early 4th instar larvae were tested with different concentrations of deltamethrin in $100 \mathrm{~mL}$ water. The concentrations were calculated according to the stock and applied directly to $100 \mathrm{~mL}$ water. The control group consisted of 20 larvae in $100 \mathrm{~mL}$ water without insecticide solution but with acetone. Each bioassay tested a minimum of six concentrations with at least three replicates per concentration. Larval mortality was recorded after $24 \mathrm{~h}$ and LC values were calculated using dosage-mortality regression probit analysis (Finney 1971). Larvae were considered dead if they could not be induced to move when probed with a needle.

Selection pressure was applied up to the $\mathrm{F}_{10}$ generation, according to the corresponding $\mathrm{LC}_{50}$. A group of 1,000 larvae were collected in each enamel tray containing $3 \mathrm{~L}$ of clean water and were treated with deltamethrin. A total of 3,000 larvae randomly collected from each generation were considered for selection pressure. Approximately 1,400-1,600 larvae survived from each generation to form the next generation. Survivors were collected after $24 \mathrm{~h}$ and reared as mentioned above. The estimation of $\mathrm{LC}_{50}$ and $\mathrm{LC}_{90}$ values served to monitor the levels of susceptibility to deltamethrin in successive generations. The resistance ratio $\left(\mathrm{RR}_{50}\right)$ was calculated by comparing the $\mathrm{LC}_{50}$ of each filial generation with the $\mathrm{LC}_{50}$ of the susceptible parent generation $\left(\mathrm{F}_{0}\right)$.

Adult bioassay - After selection with deltamethrin in each generation, larvae were reared to the adult stage and the evolution of deltamethrin resistance/tolerance was monitored with the WHO adult diagnostic test (WHO 1998). Adult female Cx. quinquefasciatus were exposed for $1 \mathrm{~h}$ to a diagnostic dose of deltamethrin ( $0.05 \%)$. For each generation, four replicates were used along with one control. Groups of 20 mosquitoes were introduced into tubes containing deltamethrin-impregnated filter paper; the control tube contained filter paper with only carrier solvent. After $1 \mathrm{~h}$ of exposure, mosquitoes were transferred to holding tubes and provided with cotton pads soaked with $10 \%$ sugar solution. Mortality was recorded after $24 \mathrm{~h}$. Resistance status was evaluated according to the WHO criteria (WHO 1992), which classify mortality rates of less than $80 \%$ as indicative of resistance while those greater than $98 \%$ indicate susceptibility. Mortality rates between $80-98 \%$ suggest the possibility of resistance that needs to be verified. The increase in tolerance and/or resistance level in adults after 10 generations was calculated by comparing the mortality of the $\mathrm{F}_{10}$ generation with the mortality of the susceptible parent generation $\left(\mathrm{F}_{0}\right)$. This comparison can be a good indicator of the quality of a resistant population.

Data analysis - Abbott's formula was used to correct the observed mortality. The $\mathrm{LC}_{50}$ and $\mathrm{LC}_{90}$ values were estimated with the help of computer software (STATPACK 2.0) developed by the Defence Research Laboratory, Tezpur (unpublished); the programme is based on dosage-mortality regression probit analysis (Finney 1971).

\section{RESULTS}

In the present study, $C x$. quinquefasciatus larvae were selected for 10 generations and each generation was tested for susceptibility to deltamethrin using the dosage-mortality relationship (Table I). Under continuous selection pressure, the $\mathrm{LC}_{50}$ and $\mathrm{LC}_{90}$ values increased steadily in subsequent generations. The first significant spike in $\mathrm{LC}_{50}$ was observed in the $\mathrm{F}_{5}$ generation (5.616 $\mu \mathrm{g} / \mathrm{L})$. An approximately 298 -fold increase in $\mathrm{LC}_{50}$ was observed based on the $\mathrm{RR}_{50}$ (Table I). The slopes of the regression curves for each generation were calculated and varied from 1.537-2.552 (Table I). The highest value was observed in the $\mathrm{F}_{10}$ generation and the lowest in the $\mathrm{F}_{3}$ generation. Small $\chi^{2}$ values indicated that the probit regression curves were very satisfactory representations of the mosquitoes' responses to log doses of deltamethrin in susceptibility tests and that they completely fit a linear model (Table I).

Deltamethrin-selected larvae from each generation were reared to the adult stage and tested for adult susceptibility to a diagnostic dose of deltamethrin $(0.05 \%)$. The results of the adult bioassays for successive generations are presented in Table II. The survival rate of mosquitoes after $24 \mathrm{~h}$ of diagnostic dose treatment indicates that resistance increased in the adult population. In our experiment, the parent colony $\left(\mathrm{F}_{0}\right)$ was completely 
susceptible to deltamethrin, as evidenced by the $100 \%$ mortality (Table II). Partial survival was first observed in the $\mathrm{F}_{2}$ generation. The mortality began to decline significantly from the $\mathrm{F}_{5}$ generation $(85 \%)$ onwards. The highest rate of survival $(65 \%)$ was recorded in the $\mathrm{F}_{10}$ generation. There was only a 2.86 -fold increase in the tolerance and/or resistance level in the adults emerged from larvae selected with deltamethrin. The continuous decline in percent mortality was indicative of increasing resistance to deltamethrin in the adults.

\section{DISCUSSION}

The slope of a regression line represents the rate of increase of probit (probability unit) per unit increase of log dose (Finney 1971). Theoretically, a colony composed of completely susceptible individuals will yield the highest slope for a dose-response regression line. With selective pressure from exposure to insecticides, a population will become heterozygous for resistant genotypes and as the frequency of resistant genotype increases, the slope of the regression line will drop off and the line will shift to the right (Brown \& Pal 1971). In our selection experiments, the slope of the regression line declined over time at the beginning because there was an increase in the heterogeneity of the population as selection pressure favoured an increased frequency of resistant alleles. Later, as selection progressed, heterogeneity tended to decrease because the resistant individuals were constantly selected, resulting in an increase in the slope of the regression line (Table I).

The results of our experiment showed that a high level of physiological resistance to deltamethrin could develop in $C x$. quinquefasciatus under continuous selection pressure. Resistance is shown by the low mortality of offspring from parents that survived selective pressure in preceding generations. A significant increase in LC values in larvae was recorded over 10 generations of selective pressure. There was an approximately 298 -fold increase in the $\mathrm{LC}_{50}$ value of deltamethrin in the $\mathrm{F}_{10}$ generation compared to the parent colony $\left(\mathrm{F}_{0}\right)$, as measured by the $R_{50}$. There was a significant increase in $R_{50}$ in preceding generations, indicating rapid development of resistance in the larval colony. The results of the present study are in line with those of Thomas et al. (1991), who reported that 40 generations of deltamethrin exposure resulted in a 1,449-fold increase in tolerance in $C x$. quinquefasciatus and those of Wang (2000), who also reported that 12 generations of deltamethrin selection in Anopheles sinensis from Zhejiang resulted in a 190-fold increase in tolerance. Another study (Li et al. 2002) with larvae of Culex pipiens pallens selected with deltamethrin showed that a nearly 531.85 -fold increase in resis-

\section{TABLE I}

Dynamic change of deltamethrin susceptibility in the colony of Culex quinquefasciatus based on dose/mortality relationships

\begin{tabular}{lccccccc}
\hline Generation & $\begin{array}{c}\mathrm{LC}_{50} \\
(\mu \mathrm{g} / \mathrm{L})\end{array}$ & $95 \%$ confidence, $\mathrm{FL}^{a}$ & $\begin{array}{c}\mathrm{LC}_{90} \\
(\mu \mathrm{g} / \mathrm{L})\end{array}$ & $95 \%$ confidence, $\mathrm{FL}^{a}$ & $\chi^{2}$ & $\mathrm{Y}=\mathrm{a}+\mathrm{bx}^{b}$ & $\mathrm{RR}_{50}$ \\
\hline $\mathrm{F}_{0}$ & 0.409 & $0.296-0.521$ & 1.463 & $0.761-2.165$ & 0.7338 & $3.5862+2.312 \mathrm{x}$ & 1 \\
$\mathrm{~F}_{1}$ & 0.599 & $0.425-0.774$ & 2.671 & $1.309-4.034$ & 0.9417 & $3.4661+1.972 \mathrm{x}$ & 1.465 \\
$\mathrm{~F}_{2}$ & 0.723 & $0.484-0.961$ & 3.383 & $1.741-5.025$ & 0.9682 & $3.3598+1.910 \mathrm{x}$ & 1.768 \\
$\mathrm{~F}_{3}$ & 0.917 & $0.573-1.261$ & 6.241 & $2.669-9.812$ & 0.6992 & $3.5211+1.537 \mathrm{x}$ & 2.242 \\
$\mathrm{~F}_{4}$ & 1.895 & $1.248-2.542$ & 11.201 & $3.948-18.455$ & 0.7819 & $2.8808+1.659 \mathrm{x}$ & 4.633 \\
$\mathrm{~F}_{5}$ & 5.616 & $3.88-7.352$ & 27.946 & $11.497-44.394$ & 0.9468 & $3.6235+1.837 \mathrm{x}$ & 13.731 \\
$\mathrm{~F}_{6}$ & 9.659 & $6.712-12.605$ & 46.277 & $20.278-72.276$ & 0.4211 & $3.1472+1.882 \mathrm{x}$ & 23.617 \\
$\mathrm{~F}_{7}$ & 13.872 & $9.41-18.334$ & 66.867 & $32.382-101.352$ & 0.2724 & $2.8597+1.874 \mathrm{x}$ & 33.917 \\
$\mathrm{~F}_{8}$ & 38.109 & $25.316-50.902$ & 181.568 & $66.7-296.436$ & 0.5325 & $3.9031+1.888 \mathrm{x}$ & 93.176 \\
$\mathrm{~F}_{9}$ & 75.093 & $56.09-94.096$ & 266.226 & $164.676-367.777$ & 0.72 & $2.9610+2.329 \mathrm{x}$ & 183.602 \\
$\mathrm{~F}_{10}$ & 121.902 & $95.025-148.779$ & 387.042 & $209.545-564.539$ & 1.2182 & $2.2295+2.552 \mathrm{x}$ & 298.049 \\
\hline
\end{tabular}

$a$ : fiducial limit; $b$ : slope of the regression line in each filial generation; RR: resistance ratio.

TABLE II

Mortality from WHO adult diagnostic test (0.05\% deltamethrin) against Culex quinquefasciatus colony selected with deltamethrin at larval stage

\begin{tabular}{|c|c|c|c|c|c|c|c|c|c|c|c|c|}
\hline & \multicolumn{11}{|c|}{ Generations } & \multirow{2}{*}{$\begin{array}{c}\text { Increase of tolerance level } \\
\text { to diagnostic dose after } 10 \\
\text { generations }\end{array}$} \\
\hline & $\mathrm{F}_{0}$ & $\mathrm{~F}_{1}$ & $\mathrm{~F}_{2}$ & $\mathrm{~F}_{3}$ & $\mathrm{~F}_{4}$ & $\mathrm{~F}_{5}$ & $\mathrm{~F}_{6}$ & $\mathrm{~F}_{7}$ & $\mathrm{~F}_{8}$ & $\mathrm{~F}_{9}$ & $\mathrm{~F}_{10}$ & \\
\hline Mortality (\%) & 100 & 100 & 97.5 & 95 & 90 & 85 & 77.5 & 68.75 & 58.75 & 48.75 & 35 & 2.86 \\
\hline
\end{tabular}


tance could develop after the $\mathrm{F}_{9}$ generation. Gayathri and Murthy (2006) studied the development of resistance against deltamethrin in Anopheles stephensi, which attained a 151 -fold increase in $\mathrm{LC}_{50}$ and 100 -fold increase in $\mathrm{LC}_{90}$ from larval selection. In another study, Kumar et al. (2004) reported a 60-fold increase in An. stephensi larval resistance to deltamethrin when selected for 40 successive generations.

Rapid development of physiological resistance against synthetic pyrethroids was also reported for adult Anopheles minimus by Chareonviriyaphap et al. (2002), who found a 27 -fold increase in $\mathrm{LD}_{50}$ after continuous selection with deltamethrin for 10 generations. In another report, Poeporn et al. (2004) found that there was a 62.29-fold increase in RR after three generations of deltamethrin selection in adult Aedes aegypti.

In our present experiment, the increase in adult resistance and/or tolerance as measured by mortality according to the WHO diagnostic test was not as significant as the 298-fold increase in resistance observed in larvae after 10 generations. However, the results are considered important as the evolution of resistance occurred in both life stages of the mosquito. Our findings are consistent with the results of Gayathri and Murthy (2006), who reported only a 6-fold increase in knockdown time $\left(\mathrm{KDT}_{50}\right)$ in adults selected at the larval stage, compared to a 151 -fold increase in resistance in larvae after 25 generations. Our findings also support those of Gayathri and Murthy (2006) in the conclusions that the development of resistance to technical deltamethrin occurs more rapidly in the larval stage and that the adults that emerge from the larval selection do not show resistance to deltamethrin to the same degree. Our results are in accord to some extent with the findings of Omer et al. (1980), who observed 28-fold higher resistance to DDT in An. stephensi adults emerged from larvae with 144-fold higher resistance. Prapanthadara et al. (1995) found that the laboratory selection of 4th instar larvae of the Zands colony of Anopheles gambiae with DDT resulted in stage-specific resistance. However, the present findings are not in agreement with those of Kumar et al. (2004), who reported no increase in the resistance of adult mosquitoes selected with deltamethrin in the larval stage for 40 successive generations. From the above discussion, it can be inferred that the intensity of selection and the development of resistance vary between different strains. Based on the results of our study presented here, it is evident that insecticide resistance can evolve in all life stages of mosquitoes and that larval selection can actually carry over to the adults, but the intensity of resistance may vary in different life stages.

Several factors other than the frequency of insecticide use influence the intensity of selection and the development of resistance in a population. The most important factors include the frequency of the resistance gene in a population, the number of genes interacting to produce the resistant character, the size of the population and the dominant relationship of the gene (Chareonviriyaphap et al. 2002). In addition, biochemical factors potentially involved in resistance mechanisms (e.g., cytochrome P-450 isoforms) could have very different expression patterns in different life stages of insects (Scott et al. 1998). Several mechanisms, including reduced sensitivity of sodium channels (i.e., $k d r$ or $k d r$-like mutations) to insecticides and over-production of detoxifying enzymes like esterase, mixed function oxidases and glutathione-S-transferases, are involved in insecticide resistance (NCR 1986, Roberts \& Andre 1994, Nelson et al. 1996, Scott et al. 1998, Feyereisen 1999). Further investigation is needed to understand and get insight into the underlying mechanisms involved in the development of resistance in the pyrethroid-resistant mosquito colony examined in the present study.

Currently, many mosquitoes throughout the world have developed resistance to all the major groups of insecticides, including biocides. Mosquito control using insecticides on a selective basis for indoor spraying, impregnated bed nets, long-lasting insecticide-treated nets, larviciding and space-spraying has therefore been accepted as a global strategy by the WHO. For the implementation of this strategy to be successful and more costeffective, it is necessary to fully understand the type and status of mosquito resistance to insecticides in relation to the practice of insecticide usage. The cross-resistance pattern, the factors responsible for resistance and their biochemical or molecular mechanisms also need to be carefully studied. Our study also provided a deltamethrin-resistant $C x$. quinquefasciatus mosquito colony, which will be used to study the action of pyrethroid insecticides and their biochemical and molecular mechanisms of resistance in Northeastern India. This can also serve as a referral strain for future resistance studies.

\section{ACKNOWLEDGEMENT}

To Mr. J. C. Aich, DRL, Tezpur, for developing and providing the software (STATPACK), to Mr. D. Goswami and Mr. B. Rabha, for their technical help during the experiment, to the reviewers, for providing certain technical details and help to improve the manuscript.

\section{REFERENCES}

Brown AWA, Pal R 1971. Insecticide resistance in arthropods, The 2nd WHO Monograph Series 38, World Health Organization, Geneva, $491 \mathrm{pp}$.

Chareonviriyaphap T, Roberts DR, Andre RG, Harlan HJ, Manguin S, Bangs MJ 1997. Pesticide avoidance behavior in Anopheles albimanus, a malaria vector in Americas. J Am Mosq Control Assoc 13: 171-183.

Chareonviriyaphap T, Rongnoparut P, Juntarumporn P 2002. Selection for pyrethroid resistance in a colony of Anopheles minimus species A, malaria vector in Thailand. J Vector Ecol 27: 222-229.

Feyereisen R 1999. Insect P450 enzymes. Annu Rev Entomol 44: 507-533.

Finney JD 1971. Probit analysis, 3rd ed., Cambridge University Press, Cambridge, 333 pp.

Gayathri V, Murthy PB 2006. Reduced susceptibility to deltamethrin and $k d r$ mutation in Anopheles stephensi Liston, a malaria vector in India. J Am Mosq Control Assoc 22: 678-688.

Kumar S, Thomas A, Sahgal A, Verma A, Samuel T, Pillai MKK 2004. Variation in the insecticide-resistance spectrum of Anopheles stephensi after selection with deltamethrin or a deltamethrin-piperonyl-butoxide combination. Ann Trop Med Parasitol 98: 861-871. 
Li X, Ma L, Sun L, Zhu C 2002. Biotic characteristics in the deltamethrin-susceptible and resistant strains of Culex pipiens pallens (Diptera: Culicidae) in China. Appl Entomol Zool 37: 305-308.

Mahanta B, Handique R, Narain K, Dutta P, Mahanta J 2001. Transmission of bancroftian filariasis in tea agro-ecosystem of Assam, India. Southeast Asian J Trop Med Public Health 31: 581-584.

NCR - National Research Council 1986. Pesticide resistance: strategies and tactics of management. In GP Georghiou, The magnitude of resistance problem, National Academy Press, Washington DC, p. 14-43.

Nelson DR, Koymans L, Kamataki T, Stegeman JJ, Feyereisen R, Waxman DJ, Waterman MR, Gotoh O, Coon MJ, Eastbrook RW, Gunsalus IC, Nebert DW 1996. P450 superfamily: update on new sequences, gene mapping, accession numbers and nomenclature. Pharmacogenet 6: 1-42.

Omer SM, Georghiou GP, Irwing N 1980. DDT-pyrethroid resistance interrelationship in Anopheles stephensi. Mosq News 40: 200-209.

Peoporn P, Supaphathom K, Srisawat R, Komalamisra N, Deesin V, Ya-umphan P, Sawat SL 2004. Biochemical detection of pyrethroid resistance mechanism in Aedes aegypti in Ratchaburi province, Thailand. Trop Biomed 21: 145-151.

Prapanthadara LA, Hemingway J, Ketterman AJ 1995. DDT-resistance in Anopheles gambiae (Diptera: Culicidae) from Zanzibar, Tanzania, based on increased DDT-dehydrochlorinase activity of glutathione S transferase. Bull Entomol Res 85: 267-274.
Prasittisuk M 1994. Comparative study of pyrethroids impregnated nets with DDT residual spraying for malaria control in Thailand, PhD Thesis, Faculty of Graduate Studies, Mahidol University, Thailand, $221 \mathrm{pp}$.

Roberts DR, Andre RG 1994. Insecticide resistant issues in vectors. Am J Trop Med Hyg 50 (Suppl.): 21-34.

Scott JG, Liu N, Wen Z 1998. Insect cytochromes P450: diversity, insecticide resistance and tolerance to plant toxins. Comp Biochem Physiol C 121: 147-155.

Singh OP, Raghavendra K, Nanda N, Mittal PK, Subbarao SK 2002. Pyrethroid resistance in Anopheles culicifacies in Surat district, Gujarat, West India. Curr Sci 82: 547-550.

Thomas A, Kumar S, Pillai MKK 1991. Piperonyl butoxide as a countermeasures for deltamethrin-resistance in Culex quinquefasciatus Say. Entomon 16: 1-10.

Wang J 2000. Resistance and response to selection to deltamethrin in Anopheles sinensis from Zhejiang, China. J Am Mosq Control Assoc 16: 9-12.

WHO - World Health Organization 1992. Vector resistance to insecticides. 15th Report of the WHO Expert Committee on Vector Biology and Control. World Health Organ Tech Rep Ser 818: 1-62.

WHO - World Health Organization 1998. Test procedure for insecticide resistance monitoring in malaria vector, bio-efficacy and persistence of insecticides on treated surfaces $(\mathrm{WHO} / \mathrm{CDS} / \mathrm{CPC} /$ Mal/98.12), WHO, Geneva, 46 pp. 